Hydrol. Earth Syst. Sci. Discuss., 8, 1329-1364, 2011

www.hydrol-earth-syst-sci-discuss.net/8/1329/2011/

doi:10.5194/hessd-8-1329-2011

(C) Author(s) 2011. CC Attribution 3.0 License.
Hydrology and Earth System

Sciences

Discussions

\title{
Assimilation of MODIS snow cover area data in a distributed hydrological model
}

G. Thirel, P. Salamon, P. Burek, and M. Kalas

European Commission, Joint Research Centre, Institute for Environment and Sustainability, Ispra, Italy

Received: 18 January 2011 - Accepted: 26 January 2011 - Published: 28 January 2011

Correspondence to: G. Thirel (guillaume.thirel@jrc.ec.europa.eu)

Published by Copernicus Publications on behalf of the European Geosciences Union.

\section{HESSD}

$8,1329-1364,2011$

MODIS SCA assimilation for discharges simulation

G. Thirel et al.

\section{Title Page}

Abstract

Introduction

Conclusions

References

Tables

Figures

14

4

Back

Full Screen / Esc

Printer-friendly Version

Interactive Discussion 


\section{Abstract}

Snow is an important component of the water cycle and its estimation in hydrological models is of great importance concerning snow melting flood events simulations and forecasting. The LISFLOOD model is a spatially distributed hydrological model 5 designed at the Joint Research Centre for large European river basins. It is used for a variety of applications including flood forecasting and assessing the effects of land use change and climate change. In order to improve the streamflow simulations of this model, especially with respect to snowmelt induced floods, the assimilation of Snow Cover Area (SCA) has been evaluated in this study. For this purpose daily $420 \mathrm{~m}$ resolution MODIS satellital SCA data have been used, which were then converted in Snow Water Equivalent (SWE) using a Snow Depletion Curve. Tests were performed over the Morava basin, a tributary of the Danube, for a period of almost three years. Two data assimilation techniques, the Ensemble Kalman Filter (EnKF) and the particle filter, were compared, for assimilating the MODIS composites of SCA every seven days. Two approaches were tested, in which the SWE of the model was adjusted either using three altitudinal-based zones or seven sub-basins-based zones. These experiments showed the improvement of the SWE of the model when compared with MODIS-derived snow for both the EnKF and the particle filter. However, on average only the particle filter improved the discharge simulation, because the EnKF imposed too important water balance modifications, which deteriorated the simulation of the discharges during the snow melt periods.

\section{Introduction}

Snow is an important component of the water cycle and of the climate evolution. Snowpacks can contain a huge quantity of water which can be released quite suddenly during the spring. Moreover, its characteristics, like the albedo, can have an important impact on surface energy fluxes. Although a lot of research has been done during the
HESSD

$8,1329-1364,2011$

\section{MODIS SCA \\ assimilation for discharges simulation}

G. Thirel et al.

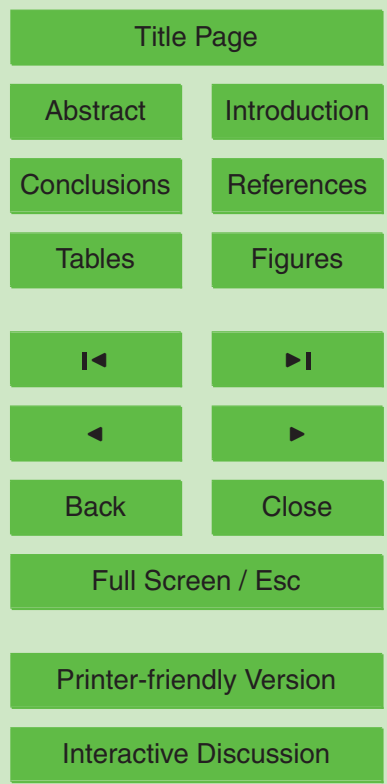


last decades concerning a better understanding of snowpack evolution and its simulation (e.g., Barnett et al., 1989; Boone and Etchevers, 2001; Decker et al., 2003) further investigation is needed especially with respect to incorporating this information into hydrologic and land surface models (LSMs, e.g., Zaitchik and Rodell, 2008; Clark et al., 5 2006).

The assimilation of observed data is a well-known technique in the field of meteorology in order to keep physical states of the models up to date. In hydrology, only in recent years its use for improving initial states, and thus the simulation of flows, water budget, or snow, has increased significantly (e.g., Salamon and Feyen, 2009; Thirel et 10 al., 2010; Reichle et al., 2002; Crow and Ryu, 2009).

Snow height observations are available over large areas on many meteorological stations. Unfortunately these data are very dependent on the local conditions (wind, vegetation, slope, sun exposition) and are therefore only of limited use in hydrological modelling. Moreover, they cannot represent the spatial variability of the snow cover in 15 a sufficiently accurate way. Therefore use of satellite observations of snow become a more and more interesting alternative especially when simulating hydrologic processes in large-scale river basin models. Indeed, such observations are usually available on a daily timestep and can cover large areas like Europe or even the entire Earth. The satellite snow observations are more and more used in the field of hydrology (e.g., 20 Andreadis and Lettenmaier, 2005; Rodell and Houser, 2004; Roy et al., 2010; Su et al., 2008; Zaitchik and Rodell, 2008; Bavera and De Michele, 2009) and are particularly suitable for the distributed hydrological or land surface models.

Snow satellite observations can be found in two forms: snow water equivalent (SWE), or Snow Cover Area (SCA). However, the quality of SWE data is often not good enough for use in hydrology, as studies found large errors in microwave estimates compared with measurements (Pulliainen et al., 2001). On the other hand, SCA data is easily available for large areas and at a relatively high sampling frequency with usually good quality (Parajka et al., 2006). Therefore, its use in hydrologic modeling has been increasing in recent years (e.g., Rodell and Houser, 2004). SCA consists in
HESSD

$8,1329-1364,2011$

\section{MODIS SCA \\ assimilation for \\ discharges \\ simulation}

G. Thirel et al.

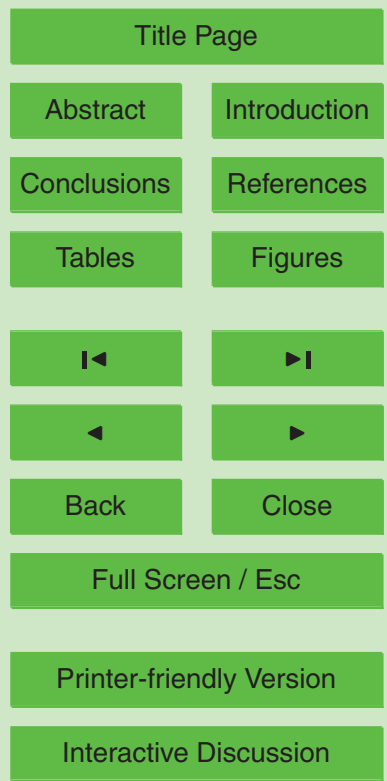


the fraction of the pixel surface covered by snow according to the image taken by the satellite. No indication about the quantity of snow (height or SWE) can be directly given by the SCA. One direct drawback of the use of satellite SCA is that these satellites cannot see "through the clouds", which means that over some periods, a lot of data can 5 be lacking. Indeed, a product like the MODIS snow data, which is the most often used snow satellite data for hydrology, can contain, for example, an average of $63 \%$ of cloud coverage over Austria (Parajka et al., 2006). To overcome these problems a variety of techniques has been developed, which mostly consists in using non-covered by clouds data from other days or from neighbouring pixels or even from interpolating data from 10 pixels at a similar altitude (e.g., Gafurov and Bardossy, 2009; Gao et al., 2010; Parajka et al., 2008, 2009).

Snow data assimilation has been tested recently in LSMs and in hydrological models. For instance, Slater and Clark (2006) implemented an Ensemble Kalman Filter to assimilate local snow depths observations into a conceptual model, and showed an 15 improvement of the simulated SWE. Clark et al. (2006) assimilated synthetic SCA information to update an hydrological model with the Ensemble Kalman Filter and observed that the SWE was improved, but not necessarily the discharges. SCA assimilation using MODIS data has been evaluated recently for instance by Rodell and Houser (2004). They used MODIS data in order to modify the snow cover of their model with a simple adding/removal method. They added $5 \mathrm{~mm}$ of snow if the model had no snow and MODIS had more than $40 \%$ of SCA, and removed the snow if the MODIS SCA was lower than $10 \%$. This work showed an improvement of snow cover by removing superfluous snow. Increase of snow happened much less frequently, mainly because of the weak quantity $(5 \mathrm{~mm})$ of snow added. Roy et al. (2010) used a combination of the MODIS data and of the NOAA Ice Mapping System (IMS) product and integrated them into the MOHYSE hydrological model with a "direct-insertion" method. This method improved the simulation of discharge peaks (Nash and RMSE) when using both MODIS data and the NASA IMS product but improved only the RMSE of discharges when only MODIS was used while the Nash coefficient was not significantly different from the one

\section{HESSD}

$8,1329-1364,2011$

\section{MODIS SCA \\ assimilation for \\ discharges \\ simulation}

G. Thirel et al.

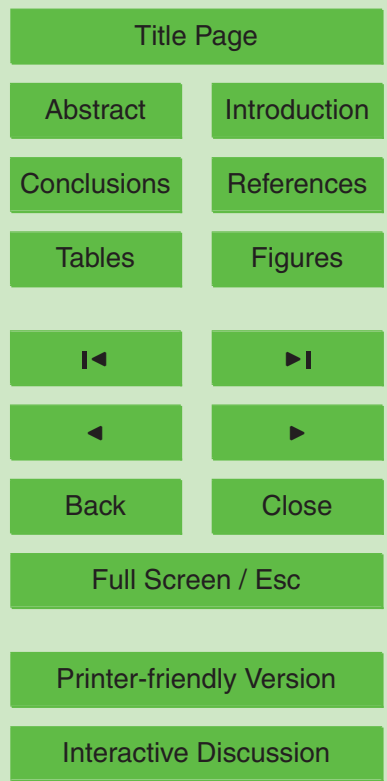


of the original simulation.

MODIS observations provide information about the presence or non-presence of snow, whereas the LSMs and hydrological models rather simulate the SWE, requiring the SCA data to be converted into SWE by specific techniques. One of these 5 approaches uses the so-called Snow Depletion Curves (SDCs) which are basically curves based on observations and characteristics of the snow, that try to fit the evolution of the quantity of snow with the SCA. Andreadis and Lettenmaier (2005) used a SDC to transform the MODIS SCA in SWE, and assimilated this "observed" snow in the variable infiltration capacity (VIC) hydrological model with an Ensemble Kalman Filter. 10 They showed the benefits of using the EnKF rather than a replacement method. Indeed, the EnKF does not modify the snow content of the model arbitrarily but takes into account different sources of errors. Su et al. (2008) assimilated MODIS SCA for North America in a LSM, illustrating its beneficial effect for the simulation of snow. Zaitchik and Rodell (2008) also used a SDC in order to convert the MODIS SCA in SWE. Their assimilation method is a push and pull algorithm, in which SWE is directly added or removed to the LSM, and the air temperature can be modified in certain cases in order to improve the snow cover. Zaitchik and Rodell (2008) could illustrate an improvement in the simulation of SCA and SWE when assimilating MODIS SCA using their approach.

The main goal of this paper is to illustrate the incorporation of MODIS SCA and 20 its related SWE (calculated with a SDC), into a distributed hydrologic model via two different data assimilation algorithms, i.e., particle filter and Ensemble Kalman filter, and to evaluate the effects on the simulation of snow and discharges. A brief review of data assimilation methods (the Ensemble Kalman Filter and the particle filter) is given in Sect. 2. Section 3 describes the MODIS data, the methods used to deal with cloud covering, and the SDC used. The LISFLOOD model is discussed in Section 4, along with the study area, the different sources of errors and the definition of the variables of the assimilation system. In Sect. 5, the results of the experiments are explained and a discussion is done in Sect. 6. Finally, the conclusions are presented in Sect. 7.

\section{HESSD}

$8,1329-1364,2011$

\section{MODIS SCA \\ assimilation for discharges simulation}

G. Thirel et al.

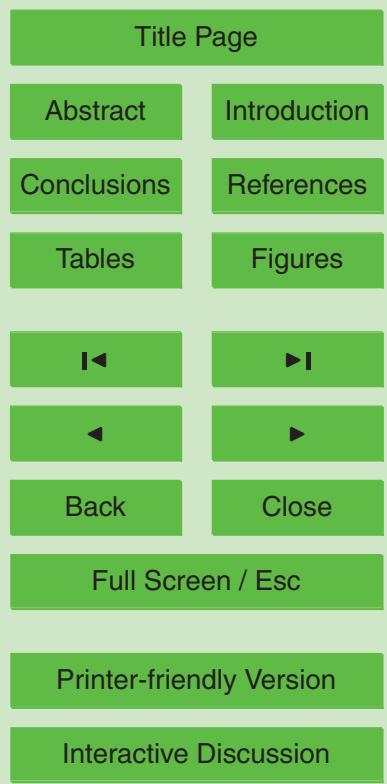




\section{Data assimilation}

A brief presentation of the theory of data assimilation and of the EnKF and the particle filter are given in this part. For further information, the reader is advised to read Doucet et al. (2001) and Simon (2006). Let $\mathbf{x}(t)$ be a vector containing the model prognostic

5 variables and $\mathbf{y}(t)$ a vector containing the available observations, at time $t . \mathbf{y}(t)$ is defined as:

$\mathbf{y}(t)=\mathbf{H}(t) \mathbf{x}(t)+\epsilon^{O}(t)$,

where $\epsilon^{o}(t)$ is its error at time $t$, defining the observation covariance error matrix $\mathbf{R}(t)$ $\left(\mathbf{R}(t)=E\left(\epsilon^{o}(t) \epsilon^{o T}(t)\right)\right)$, and $\mathbf{H}(t)$ is the measurement operator transforming the model 10 state to the observation space. If $\mathbf{Y}(t)$ represents the past and current observations, both the EnKF and the particle filter aim to estimate the conditional probability density function (pdf) $p(\mathbf{x}(t) \mid \mathbf{Y}(t))$. This pdf is assessed using Bayes' formula:

$p(\mathbf{x}(t) \mid \mathbf{Y}(t))=\frac{p(\mathbf{y}(t) \mid \mathbf{x}(t)) p(\mathbf{x}(t) \mid \mathbf{Y}(t-1))}{p(\mathbf{y}(t))}$.

The choice and definition of the states of the LISFLOOD model used in the assimilation schemes will be discussed in Sect. 4.

\subsection{The Ensemble Kalman Filter (EnKF)}

The Ensemble Kalman Filter is an approximation of the Extended Kalman Filter (Bouttier and Courtier, 1999), which means that some of its terms are estimated instead of being directly calculated (Evensen, 2003):

$\mathbf{x}^{a}(t)=\mathbf{x}^{b}(t)+\mathbf{B}(t) \mathbf{H}^{T}(t)\left[\mathbf{H}(t) \mathbf{B}(t) \mathbf{H}^{T}(t)+\mathbf{R}(t)\right]^{-1}\left(\mathbf{y}(t)-\mathbf{H}(t) \mathbf{x}^{b}(t)\right)$,

where $\mathbf{B}(t)$ is called the background state covariance error matrix, $\mathbf{x}^{b}(t)$ the background state of the model (i.e. before assimilation) and $\mathbf{x}^{a}(t)$ the analysed state (after assimilation) according to Bouttier and Courtier (1999). In this equation, $\mathbf{H}(t) \mathbf{B}(t) \mathbf{H}^{T}(t)$ 1334
HESSD

$8,1329-1364,2011$

\section{MODIS SCA}

assimilation for

discharges

simulation

G. Thirel et al.

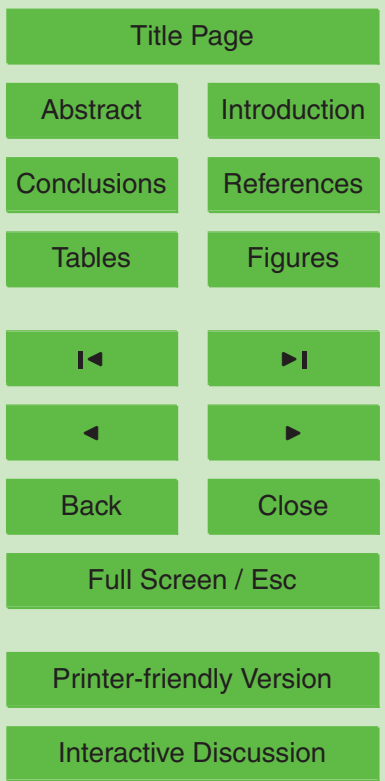


can be approximated by $\mathbf{H A}(\mathbf{H A})^{T}$ with $\mathbf{H A}=E(\mathbf{x}(t))-\mathbf{x}(t)$. As the inversion of the $\left(\mathbf{H}(t) \mathbf{B}(t) \mathbf{H}^{T}(t)+\mathbf{R}(t)\right)$ matrix can be cumbersome if this matrix has big dimensions (i.e. many observations used), we preferred not to use it as described in Evensen (2003). Instead, we re-wrote the inverse of this matrix using the Sherman-Morrison-Woodbury 5 formula (Hager (1989), note that the $(t)$ brackets are removed for an easier reading):

$\left(\mathbf{H B H}^{T}+\mathbf{R}\right)^{-1}=\mathbf{R}^{-1}\left[\mathbf{I}-\frac{1}{n-1} \mathbf{H A}\left(\mathbf{I}+(\mathbf{H A})^{T} \mathbf{R}^{-1} \frac{1}{n-1} \mathbf{H A}\right)^{-1}(\mathbf{H A})^{T} \mathbf{R}^{-1}\right]$.

Here, the only matrices to invert are $\mathbf{R}$ (a diagonal matrix, thus it has almost no computing time cost) and $\left(\mathbf{I}+(\mathbf{H A})^{T} \mathbf{R}^{-1} \frac{1}{n-1} \mathbf{H A}\right)$ whose dimensions are the dimensions of the state variable vector, which are quite often smaller than the dimensions of the observa-

tion matrix. The $\mathbf{R}$ matrix has been approximated by using the square of a white noise created with the standard deviation of the observations (Evensen, 2003). This white noise was also added to the observations during the assimilation process in order to reduce the collapse of the filter (Doucet et al., 2001).

\subsection{The Particle Filter}

15 The particle filter (Van Leeuwen, 2009; Arulampalam et al., 2002; Moradkhani et al., 2005) approximates the posterior pdf (Eq. 2) by a collection of Monte-Carlo samples ( $N$ particles), each of them being assigned by weights as follows:

$p(\mathbf{x}(t) \mid \mathbf{Y}(t)) \approx \sum_{n=1}^{N} w^{(n)}(t) \delta\left(\mathbf{x}(t)-\mathbf{x}^{(n)}(t)\right)$,

where $w^{(n)}(t)$ is the weight of the particle $n$ at time $t$ and $\delta()$ is the Dirac function. The 20 likelihood of each particle $\left(a^{(n)}(t)\right)$ was computed as follows (e.g., Simon, 2006; Chin
HESSD

$8,1329-1364,2011$

\section{MODIS SCA}

assimilation for

discharges

simulation

G. Thirel et al.

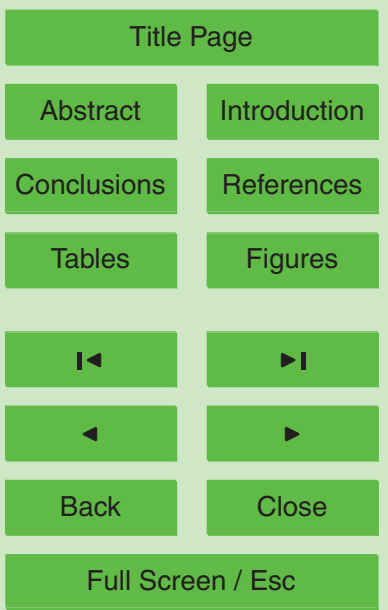

Printer-friendly Version

Interactive Discussion 
et al., 2007):

$a^{(n)}(t)=\frac{\exp \left\{-\left[\mathbf{y}(t)-\mathbf{H}(t) \mathbf{x}^{(n)}(t)\right]^{T} \mathbf{R}^{-1}(t)\left[\mathbf{y}(t)-\mathbf{H}(t) \mathbf{x}^{(n)}(t)\right] / 2\right\}}{\sqrt{\operatorname{det}(2 \pi \mathbf{R}(t))}}$.

Finally, the normalized weights of the particles were set by:

$w^{(n)}(t)=\frac{a^{(n)}(t)}{\sum_{i=1}^{N} a^{(i)}(t)}$

5 In order to avoid filter degeneracy the particles are resampled using stochastic universal sampling (Baker, 1987).

\section{MODIS}

MODIS (or Moderate Resolution Imaging Spectroradiometer) is a key instrument aboard the Terra and Aqua satellites. Terra's orbit around the Earth is timed so that

10 it passes from North to South across the equator in the morning, while Aqua passes from South to North over the equator in the afternoon. Terra MODIS and Aqua MODIS are covering the entire Earth's surface every 1 to 2 days, acquiring data using 36 spectral bands or groups of wavelengths. The role of MODIS is to provide help to the development of global interactive Earth system models for global change prediction.

15 It aims to assist policy makers for the decisions regarding the environment protection (http://modis.gsfc.nasa.gov/about/).

\subsection{The data}

The MODIS data used in this study were downloaded from the WIST website (see website: https://wist.echo.nasa.gov/api/). Daily data from the Terra and Aqua satellites

\section{HESSD}

$8,1329-1364,2011$

\section{MODIS SCA}

assimilation for discharges simulation

G. Thirel et al.

\section{Title Page}

Abstract

Introduction

Conclusions

References

Tables

Figures

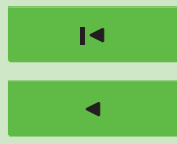

$\rightarrow$

Back

Close

Full Screen / Esc

Printer-friendly Version

Interactive Discussion 
were downloaded from 1 July 2003 to 10 December 2006 (Hall et al., 2000) for the study area, which are included in two MODIS tiles: h19v03 and h19v04. The grid cell size for our area was approximately $420 \mathrm{~m}$. The provided pixels values are ranked in different categories as shown in Table 1. According to this ranking we grouped the 5 categories 100 and 200 as snow pixels, categories 25, 37 and 39 were no-snow pixels, and the other categories were grouped in the category no-data ("we don't know"). The SCA maps described below (before aggregation on the LISFLOOD $5 \mathrm{~km}$ grid) thus contain three types of values: 1 for snow, 0 for no-snow, and missing values for nodata (Table 1).

\subsection{Preprocessing of SCA data}

Due to the frequently high proportion of cloud coverage, several steps were needed to prepare the data for the assimilation procedure. After combining the Aqua and Terra data, on average $48.6 \%$ of clouds were still present in the study area and for the concerning period (Table 2), which was too much to give an actual added value to the use of this data. Consequently, several spatio-temporal combinations and regional snow-line methods described and evaluated by Parajka et al. (2008) and Parajka et al. (2009) were used in this study. All these methods were realized at the original resolution of MODIS.

The first step was to use the combined Aqua and Terra snow cover maps of the seven previous days. This method assumes that the snow cover is not evolving fast for such a short period of time, and that during a 7-day period, most of the area would have at least one cloud-free satellite image. As detailed in Table 2, this method is significantly reducing the cloud coverage over the Morava basin, from a value of $48.6 \%$ of cloud coverage when only using the current day data, to a value of $4.9 \%$ of cloud coverage

after using the combined Aqua/Terra maps from day -1 to day -7 . Figure 1 illustrates the effects of merging Aqua and Terra images and then combining it with the previous days observations for the 24 December 2005. After this temporal combination, most of the basin appears to be cloud-free for this date.

HESSD

8, 1329-1364, 2011

MODIS SCA

assimilation for discharges simulation

G. Thirel et al.

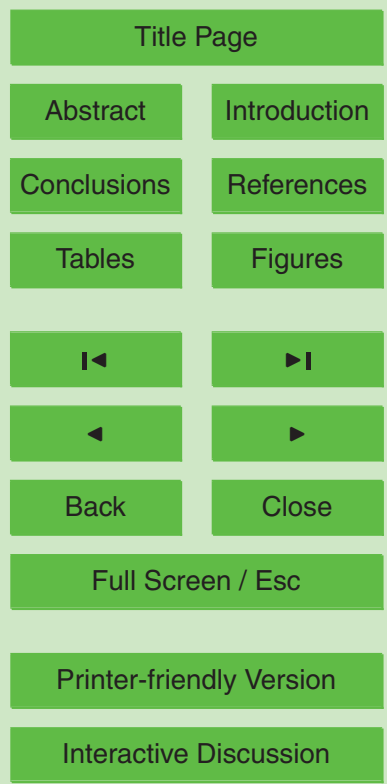

Interactive Discussion 
However, certain points still show missing values. Thus we furthermore applied a neighbouring method. Here, each pixel presenting a missing value was affected according to the average of the values of its close (eight) neighbours: 1 if $0.5<$ average $\leq$ 1,0 if $0 \leq$ average $\leq 0.5$ and missing value if none of its neighbours had a value.

Finally, a regional snow-line method was used. For this purpose, the average altitude of all the snow pixels (snow_alt) and the average altitude of all the no-snow pixels (no_snow_alt) were computed. Then, the pixels remaining with missing values were allocated to 1 if their altitude was higher than snow_alt and to 0 if their altitude was lower than no_snow_alt. The pixels with missing values and an altitude comprised between 10 snow_alt and no_snow_alt were assigned to 0.5 , which means a partial snow cover. At this step, all the pixels of the Morava basin were attributed with a value (see Fig. 1).

The last step was to aggregate this final map to the resolution of the model $(5 \mathrm{~km})$, which gave the last image of Fig. 1. This final map was used by the assimilation system.

\subsection{Conversion from SCA to SWE}

15 Hydrologic models usually require information about SWE for their simulation and thus, a method is required to transform the MODIS SCA data aggregated on the LISFLOOD $5 \mathrm{~km}$ grid into SWE.

This transformation can be done using a Snow Depletion Curve (e.g., Su et al., 2008; Andreadis and Lettenmaier, 2005). We chose the SDC description given in 20 Zaitchik and Rodell (2008) as additional data requirements are low and it has proven to approximate SWE reasonably well (Zaitchik and Rodell, 2008):

$\mathrm{SCA}=\min \left\{1-\left[\exp \left(-\frac{\tau \mathrm{SWE}}{\operatorname{SWE}_{\mathrm{SCA}=1.0}}\right)-\frac{\operatorname{SWE}}{\operatorname{SWE}_{\mathrm{SCA}=1.0}} \exp (-\tau)\right], 1.0\right\}$,

where SCA is the fraction of each LISFLOOD pixel covered by snow according to MODIS, SWE SCA $=1_{1}$ defines the minimum SWE required for full snow cover for a specific

land use and $\tau$ is a shape parameter relating the total amount of snow to the snow cover fraction in a pixel. In this study, we follow Zaitchik and Rodell (2008) and assign 1338

\section{HESSD}

$8,1329-1364,2011$

MODIS SCA

assimilation for

discharges

simulation

G. Thirel et al.

Title Page

Abstract

Introduction

Conclusions

Tables

References

Figures

14

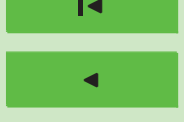

$\rightarrow 1$

Back

Close

Full Screen / Esc

Printer-friendly Version

Interactive Discussion 
$S_{W E A=1}$ values ranging from $13 \mathrm{~mm}$ for bare soil, $20 \mathrm{~mm}$ for sparse forest and $40 \mathrm{~mm}$ for full forest coverage. $\tau$ was set to four like in Zaitchik and Rodell (2008).

As the SCA values are directly given by the MODIS data as described previously, all parameters in Eq. (8) are known and the corresponding SWE can be calculated 5 by inverting Eq. (8). For doing this, the dependency of the SWE upon the SCA was approximated by a second order equation fitting. Observed SCA values higher than 0.8 were not used in order to avoid a too high sensivity of the fitted depletion curve for this interval.

\section{Hydrological model and set up of the assimilation system}

\subsection{The LISFLOOD model}

In this work we used the spatially distributed, partially physically-based LISFLOOD model (De Roo, 1999; Van der Knijff et al., 2008) which is developed at the Joint Research Centre (JRC, European Commission) for simulating discharges in large-scale river basins in Europe. The model is raster based and is implemented using a com-

Python scripting language facilitating the handling of large data sets.

Physically based, soil and land use related parameters have been derived from various databases (King et al., 2004; Wösten et al., 1999; European Environment Agency, 2000). The meteorological inputs of LISFLOOD are spatially distributed data like precipitation, temperature, wind speed and others, which are derived from the Meteorological Archiving and Retrieving System (Rijks et al., 1998), the World Meteorological Organizations synoptic observations (http://www.wmo.int/pages/prog/www), and the German Weather Service (http://www.dwd.de/). Although LISFLOOD is based on physics to a certain extent, some processes are only represented in a conceptual way. 25 For the calibration of the Danube basin we used nine parameters that need to be estimated against measured streamflow records. The following gives an overview on the
HESSD

8, 1329-1364, 2011

\section{MODIS SCA \\ assimilation for discharges simulation}

G. Thirel et al.

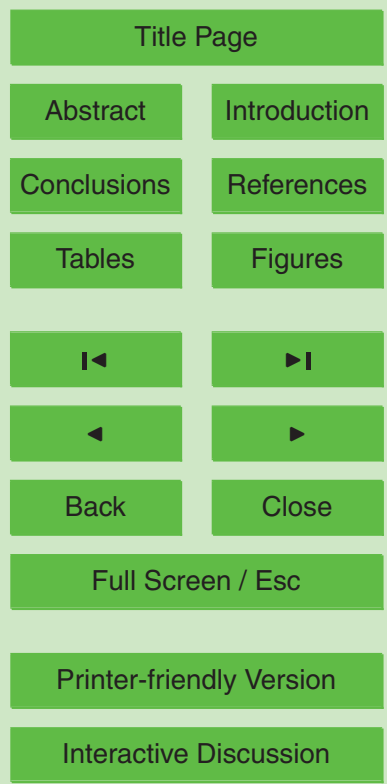


structure of LISFLOOD. The simulation of fast sub-surface flow through macro-pores (preferential flow) is assumed to be a non-linear function of the relative saturation of the topsoil. For the remaining water that falls on the soil surface, infiltration and surface runoff are simulated using the Xinanjiang approach (Zhao and Liu, 1995; Todini, 1996).

5 The moisture fluxes out of the top- and subsoil are calculated assuming that the flow is entirely gravity-driven. The groundwater system is described using two parallel interconnected linear reservoirs, similar to the HBV-96 model (Lindström et al., 1997). The upper zone represents a mix of fast groundwater and sub-surface flow. The lower zone has a much slower response and generates the base-flow. Routing of water through 10 the river channel is done on the $5 \mathrm{~km}$ raster at European scale with the kinematic wave descriptions (Chow et al., 1988). Special structures such as lakes, water reservoirs and retention areas can be simulated by giving their location, size and in- and outflow boundary conditions.

The simulation of the Snow Water Equivalent which will be updated using the MODIS 15 data, can be described as follows. If the temperature is below $1^{\circ} \mathrm{C}$, all precipitation is assumed to be snow. Snow melt is simulated using a simple degree-day factor. This factor is depending on the temperature above the meltpoint temperature $\left(0^{\circ} \mathrm{C}\right)$, the rainfall rate, and a calibrated coefficient called the snow melt coefficient (Speers et al. (1979)):

20 snow_melt $=C(1+0.01 R) T$,

where $C$ is the snow melt coefficient, $R$ is the daily rainfall and $T$ is the daily temperature. As LISFLOOD is using large pixels $(5 \times 5 \mathrm{~km})$, the sub-pixel heterogeneity in snow accumulation and snow melt is taken into account by modelling these processes for three separate elevation zones. For this, a normal distribution was used to split used inside the model in order to modify the snow melt coefficient according to the season (Anderson, 2006). This assumption relies on the fact that because of the snow albedo and of the solar radiation modifications along the year, the snow melt is more important during the summer. Finally, an additional snow melt process was added for

\section{HESSD}

$8,1329-1364,2011$

\section{MODIS SCA \\ assimilation for discharges simulation}

G. Thirel et al.

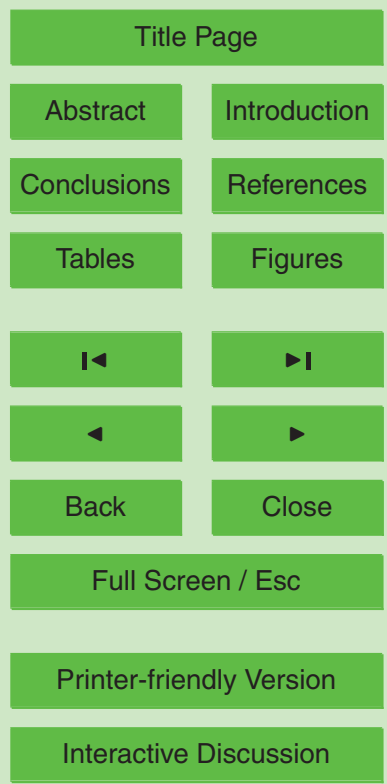

Interactive Discussion 
periods from 15 June to 15 September in order to mimic glaciers melt (see LISFLOOD user manual, Burek and de Roo, 2011).

The hydrological simulations are computed at a daily timestep. The Ensemble Kalman Filter and the particle filter were implemented using a combined PCRaster 5 and Python framework for data assimilation (Karssenberg, 2010).

\subsection{Case study}

The study area of this paper is the Morava basin, which is a tributary of the Danube river, located mainly in the Czech Republic (see Fig. 2). The Morava basin area is around $26000 \mathrm{~km}^{2}$ with an elevation ranging from $120 \mathrm{~m}$ to almost $1500 \mathrm{~m}$. Daily discharge data were available for our study area at seven gauge stations in the basin. Daily snow depth data were available for 11 meteorological stations for the area, situated at an elevation between $200 \mathrm{~m}$ and $580 \mathrm{~m}$ a.s.l.

Experiments were realized for the period from 1 July 2003 to 10 December 2006. A 6-month spin-up period was used, so that scores presented were computed for the 15 period from 10 January 2004 to 10 December 2006, on which discharge data were available for each station. However, scores comparing with snow depths from the seven meteorological stations were computed from 5 April 2005 to 10 December 2006 only, because data were not available for a longer period. The assimilation timestep was seven days, which we considered a reasonable compromise between the computing time and the time evolution of the snow cover.

\subsection{Sources of errors}

The simulation of SWE in LISFLOOD is mainly influenced by three factors: precipitation, temperature, and snow melt coefficient. Hence, random errors have been added to these factors in order to generate the members/particles for the EnKF and the particle filter, which aim at estimating the probability density functions of these parameters. Each pixel of the daily precipitation fields was multiplied by a value between 0.5

HESSD

$8,1329-1364,2011$

MODIS SCA

assimilation for discharges simulation

G. Thirel et al.

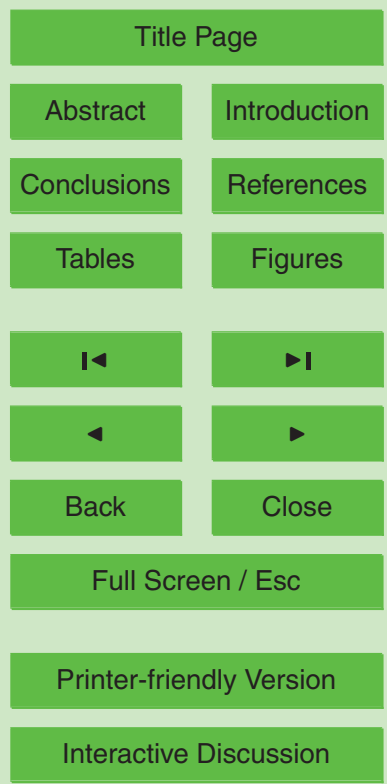


and 1.5, drawn from a uniform distribution. For the daily temperature, a value from a uniform distribution between $-3^{\circ} \mathrm{C}$ and $+3^{\circ} \mathrm{C}$ was added to each pixel, which is slightly higher than the RMSE reported in Quintana et al. (2008) for example. Finally, the snow melt coefficient was created with a uniform distribution for each pixel in the 5 range of the usual values of the calibrated parameter for LISFLOOD (between 2.5 and $5.5 \mathrm{~mm}^{\circ} \mathrm{C}^{-1}$ day $^{-1}$ ).

\subsection{Definition of the variable state and the observation state}

The variable state $\mathbf{x}(t)$ and the observation state $\mathbf{y}(t)$ given in Eq. (1) both represent snow: $\mathbf{x}(t)$ is the SWE in the model, and $\mathbf{y}(t)$ is the SWE converted from the MODIS

10 SCA observations. In this work, we evaluated two different approaches to calculate the variable state and the observation state. The first approach sums up the grid values over three zones which are defined according to the altitude of the pixel (Fig. 3, left): altitude lower than $300 \mathrm{~m}$, between $300 \mathrm{~m}$ and $600 \mathrm{~m}$, and higher than $600 \mathrm{~m}$. The second approach divides the river basin into several sub-basins according to the drainage direction network and to the availability of gauging station data (Fig. 3, right). This resulted in seven sub-basin zones where the outflow point of each sub-basin zone corresponds to the gauging station location as shown in Fig. 2. Only MODIS values lower than 0.8 were used for the calculation.

For each experiment, $\mathbf{x}(t)$ and $\mathbf{y}(t)$ were defined in the same way, i.e. gridded values 20 were summed over the same zones for a single experiment. Thus, $\mathbf{H}(t)$ in Eq. (1) represents the identity matrix, because the variable state and the observation state are defined in the same space. Hence, likelihoods were calculated for each of the subbasins/zones and then averaged for the particle filter, whereas the EnKF was applied to each of these sub-basins/zones separately.

25 The observation error has been set to $5 \mathrm{~mm}$ for each observation state for the particle filter and it was assumed that there was no correlation between the observation states, so the $\mathbf{R}(t)$ matrix is a diagonal and constant matrix with a value of 25 on its diagonal.

\section{HESSD}

$8,1329-1364,2011$

\section{MODIS SCA \\ assimilation for discharges simulation}

G. Thirel et al.

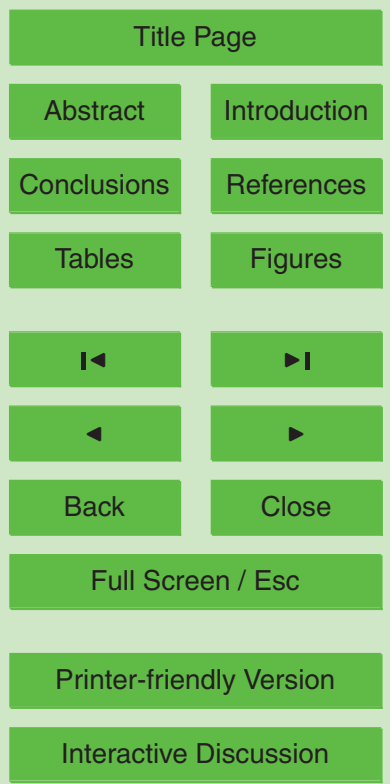




\section{Results}

The EnKF and the particle filter were run for the Morava basin for both the three altitudinal zones case and the seven sub-basins-based zones case for more than three years (from 1 July 2003 to 10 December 2006). In addition, for each case the influ5 ence of the number of members and particles was assessed, using 20 or 50 members for the EnKF, and 50 or 200 particles for the particle filter. For the discharges, daily observations were used as the reference for scores calculation, and scores were averaged for the seven gauge stations. Moreover, scores were also computed comparing the simulations with snow depth measurements at 11 meteorological stations, for the

105 April 2005-10 December 2006 period. The snow depth measurements were converted into SWE using a snow density function which evolves during the snow season as described in Bavera (2008) and Bavera and De Michele (2009) and scores were then averaged over all stations. The ratio-RMSE and the ratio-bias were computed for both snow and discharges, and the Nash criterion was computed for discharge only.

15 Furthermore, scores were calculated for the mean of the $\mathbf{2 0}$ or $\mathbf{5 0}$ members, or for the 50 or 200 particles, respectively.

Table 3 shows the scores for the four assimilation experiments using the three altitudinal zones, and for a simulation without assimilation. When compared with the MODIS-derived SWE, the snow ratio-RMSE and the Ratio-Bias were improved for all four experiments. When compared with in-situ observations, the EnKF with 20 members and the particle filter with 50 particles deteriorated the scores, whereas the EnKF with 50 members and the particle filter with 200 particles improved them. Concerning the scores of discharges, it is remarkable to see that overall the scores improved for the particle filter, but deteriorated for the EnKF (only the Ratio-Bias was improved there). Indeed, for the particle filter, all three scores show an improvement (i.e., reduction of the ratio-RMSE and ratio-Bias and increase of the Nash criterion). On the other hand, for the EnKF, the Ratio-RMSE increased, the Nash criterion decreased; only the Ratio-Bias improved slightly.

\section{HESSD}

$8,1329-1364,2011$

\section{MODIS SCA \\ assimilation for discharges simulation}

G. Thirel et al.

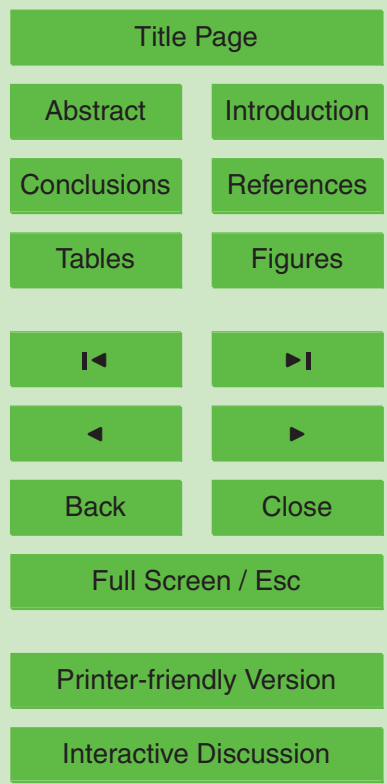


Table 4 shows the scores for the assimilation experiments using the seven subbasins zones. A similar behaviour as in the previous experiments is observed here. The scores improved for the four experiments for the SWE compared with the MODISderived SWE, but only the particle filter improved the discharges. Here, the EnKF 5 deteriorated all scores for discharges, the Ratio-RMSE, the Ratio-Bias and the Nash criterion. The comparison with in-situ snow measurements showed that the particle filter improved the scores whereas the EnKF did not.

Generally, the results suggest that the more members/particles were used, the better were the in situ snow scores when using the same data assimilation algorithm, except 10 for the particle filter case using seven sub-basins (Tables 3 and 4). However, the impact of the number of members/particles was very low concerning discharges scores and MODIS snow scores. The only significant difference was for the EnKF using the seven zones approach. For this case we can see that using more members improved less snow scores, which resulted in less deteriorated discharges scores.

15 Concerning the difference between using three altitude-based zones or seven subbasins-based zones, the EnKF and the particle filter behaved differently. The EnKF showed a better improvement of the MODIS snow scores when using the seven zones. This can be explained by the fact that, because the EnKF directly modified the SWE on each zone on which the variables were defined, the more zones it could modify separately, the stronger was the improvement. However, the improvement (resp. deterioration) of the MODIS derived snow scores was not necessarily linked to an improvement (resp. deterioration) of the in situ snow scores. This suggests that due to the large uncertainty in snow density, the strong influence of the local conditions on the measured snow depths as mentioned previously, and the low number of available data, the value

\section{HESSD}

$8,1329-1364,2011$

\section{MODIS SCA \\ assimilation for \\ discharges \\ simulation}

G. Thirel et al.

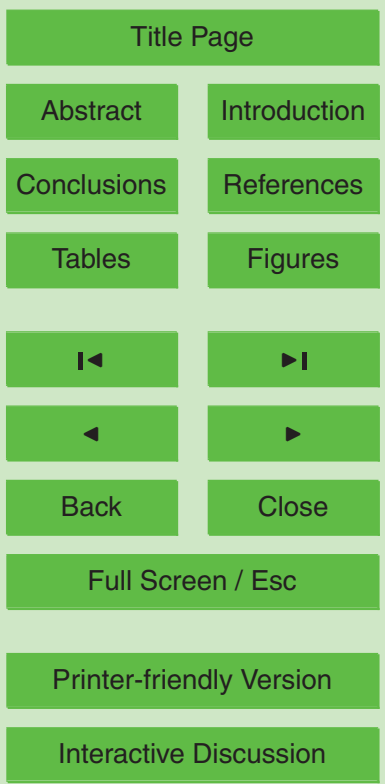




\section{Discussion}

As shown in the Results section, although the EnKF was equally or more efficient than the particle filter in improving the snow simulation (for MODIS-related SWE scores) the results of this work suggest that simulated discharges in our distributed model are 5 deteriorated when assimilating SCA using the EnKF. That is why a further discussion is needed on this aspect of the results. First, one could assume that because the EnKF modified the SWE too much (see Table 4), the LISFLOOD parameters were not anymore relevant with the new distribution and amount of snow. However, when looking at the scores for the experiment using the three zones (Table 3), we can see that the MODIS-related snow scores were very similar for the EnKF and the particle filter, but it resulted in discharges scores which are improved for the particle filter, but deteriorated for the EnKF. In Fig. 4 (top), discharges are plotted for the gauge station number 6 (eastern part of the basin) as indicated in Fig. 2 from 1 February 2006 to 10 July 2006, where an important flood event occurred in April 2006, for the particle filter using 200 particles (left) and for the EnKF using 50 members (right), using the three altitudebased zones. The graphs show that the peak of this flood was over-estimated by the original LISFLOOD simulation in this case. The experiments using SCA assimilation showed an improved simulation of this peak, slightly too high for the particle filter, but too low for the EnKF, with a narrow uncertainty for both discharge simulations. The bottom part of Fig. 4 shows the evolution of the average of the SCA over the upstream area of station 6 for the same period. The uncertainty in SCA was quite high until April and quasi null from May onwards for both assimilation techniques. However, the mean SCA for February and March was very close to one for both experiments, indicating that only a few members/particles had a low SCA for this period. The main snow extent depletion which occurred according to MODIS at the very beginning of April, began earlier with the particle filter and the original simulation, but began at the correct moment with the EnKF. Another difference is that the SCA was higher with the

\section{HESSD}

8, 1329-1364, 2011

\section{MODIS SCA \\ assimilation for discharges simulation}

G. Thirel et al.

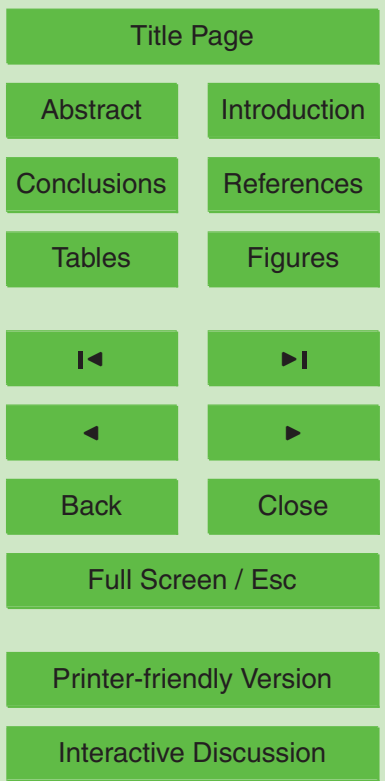


EnKF than with the particle filter before and just after the main snow melt period.

Figure 5 (top) shows the normalized differences between the observed discharges and the simulated discharges for station 6 (for the same experiments that are shown in Fig. 4 and for the no assimilation run). This figure shows that the discharge peak 5 at the beginning of April was over-estimated by the original simulation of LISFLOOD (the black line went into the negative at the beginning of April) and that the particle filter curve fitted this line better than the EnKF, indicating that it improved the discharges. The EnKF curve was positive during this event, suggesting that discharges were underestimated. The bottom part of Fig. 5 shows the normalized differences between the 10 SWE resulting from the particle filter or the EnKF experiment, and the one coming from the no assimilation simulation. Figure 5 (bottom) illustrates that the SWE was very similar for both the particle filter and the EnKF before the beginning of the snow extent depletion period (second half of March) and lower than for the original simulation of LISFLOOD. During the snow extent depletion period, a slight difference can be observed (the experiment using the EnKF simulated more snow at the beginning of this period), but seemed low, whereas the difference in discharges was higher for the peak with no compensation during the later decrease of flow (i.e. much less discharges simulated with the EnKF). For the particle filter the snow depletion resulted necessarily in a snow melt as the particle filter does not modify state variables directly. On the contrary, the EnKF removed SWE directly from the model and consequently modified the water balance, which then had the effect that simulated discharges were too low in comparison to the observations. Therefore, our results suggest that the particle filter appears to be the best solution when assimilating MODIS SCA in order to improve streamflow simulations in distributed hydrological models.

Figure 6 shows the discharges for the same experiments for the outlet station (top) and the SCA of its upstream area (bottom). It can be observed that the peak discharge simulated with the particle filter had the correct intensity but was occurring too early, whereas the peak discharge for the EnKF experiment was too low and also occurring too early. The SCA did not seem to be modified so much by the particle filter, but was
HESSD

$8,1329-1364,2011$

\section{MODIS SCA \\ assimilation for \\ discharges \\ simulation}

G. Thirel et al.

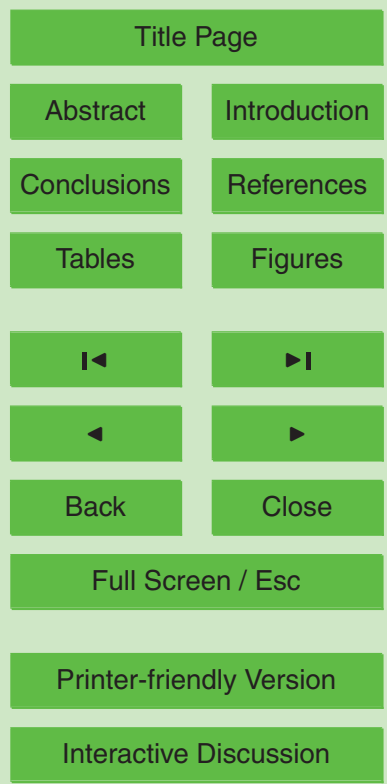


higher for the EnKF. Both experiments presented a main snow extent depletion period (i.e. abrupt SCA decrease) at the same moment and with a similar intensity. Figure 7 presents the normalized differences on discharges and SWE for the gauging station 7 . Here again during the main peak (and even some days before and some days after) 5 the discharges of the EnKF were lower than the ones of the particle filter (the curve for the EnKF experiment presented higher values during the event). However, the SWE evolution of both experiments was synchronized (Fig. 7, bottom) and with a similar intensity. These results confirm the conclusions drawn from the station 6 plots and indicate that the EnKF is not a relevant solution for improving discharge simulations 10 because it modifies directly the water balance.

\section{Conclusions}

The use of snow satellite observations like the MODIS SCA data has received an increased attention in recent studies. We presented here the benefits of using the Ensemble Kalman Filter and the particle filter for assimilating the MODIS SCA in the 15 LISFLOOD distributed hydrological model, at a 7-day frequency. The assimilation was applied to the Czech Morava river basin, a tributary of the Danube, for a time period of three years. The uncertainty in precipitation, temperature, and the snow melt coefficient parameter was taken into account by using random distributions. Two ways of defining the observation state and the variable state have been evaluated based on either three altitudinal zones or on the sub-basin structure of the Morava river. Furthermore, the importance of the number of members or particles was also investigated.

For the two sets of experiments, data (observations and model outputs) were summed over these zones. The EnKF adjusted SWE in each zone whereas the particle filter defined the likelihood of a particle by summing the likelihoods of the different zones. Both assimilation techniques used MODIS SCA observations. Due to the high cloud coverage of the MODIS data various pre-processing algorithms were applied in order to improve the quality of the data. They consisted in using data from previous

\section{HESSD}

8, 1329-1364, 2011

\section{MODIS SCA \\ assimilation for discharges simulation}

G. Thirel et al.

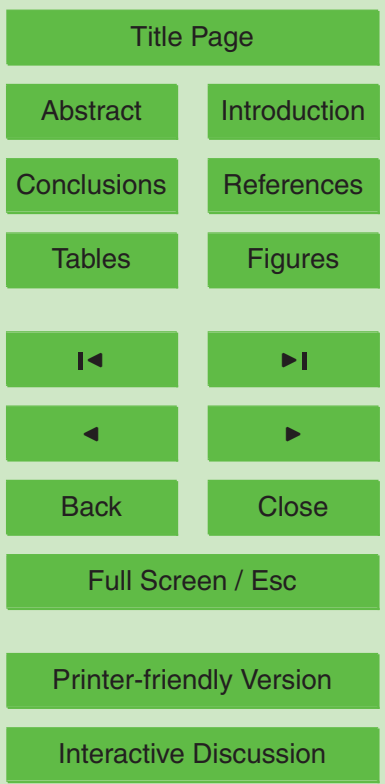


days for zones covered by clouds, and were combined by close-neighbouring methods and snow-line-based methods. Scores for assessing the effects of data assimilation were calculated for snow, using the SWE derived from the MODIS SCA over the basin as well as the SWE derived from snow depths measurements at various meteorological 5 stations. For discharges, scores were averaged over seven gauge stations.

An analysis of the impact of the number of members/particles showed that the higher the number of particles/members was, the closer to in-situ measurements the modelled SWE was, for most of the cases. However, the impact on MODIS-derived SWE scores and on discharge scores was very low. Using the three altitude-based zones or the 10 seven sub-basins-based zones had no impact on the particle filter scores. Nevertheless, the experiments illustrated that using the seven sub-basins zones lead to a better improvement of the MODIS-derived snow scores for the EnKF case as the representation of the study area in this case was finer, and thus allowed the EnKF to update the model SWE more precisely.

15 The most important feature observed in this study is that using the particle filter improved the simulated discharges as expected, but that the EnKF deteriorated simulated discharges on average, despite of improving the MODIS-based snow scores. The reason for such a behaviour of the EnKF is that the EnKF modified directly the SWE in the model, by adding or removing amounts of snow, while the particle filter only selected the particles for which the evolution of SWE was the closest to the MODIS SWE evolution and hence maintained the water balance. Indeed, it was shown that despite of the similar decrease of the SWE in both cases, the discharges were lower for the EnKF. This suggests that the EnKF removed snow in the model in order to be closer to the MODIS SCA observations, which resulted in underestimated discharges as too little snow was available for the melting process. On the other hand, in the case of the particle filter, the particles that reproduced the best this SWE diminution are those that in fact simulated an increased snow melt, and thus for this case the discharges were closer to reality. This indicates that the use of the EnKF can be a better choice in case the main goal is to improve SWE/SCA simulation. However, if data assimilation
HESSD

8, 1329-1364, 2011

\section{MODIS SCA \\ assimilation for \\ discharges \\ simulation}

G. Thirel et al.

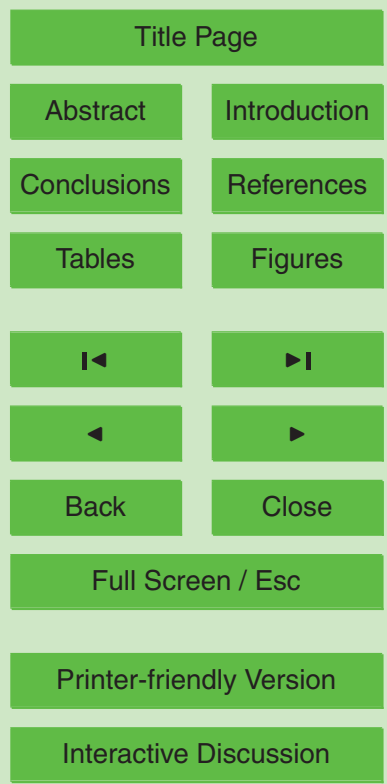


is employed to improve streamflows, like in this study, using the EnKF may on average deteriorate the results.

The use of the particle filter for assimilating SCA data seems promising. However, further work is needed before its application in operational forecasting systems. For 5 example, when applied to larger scale basins more zones have to be used during the assimilation process to take account of the heterogeneity of the snow cover. Unfortunately, a higher number of zones might also require a larger number of particles in order to prevent the collapse of the filter, which would lead to an increase in computational costs. Furthermore, for the implementation of SCA assimilation in operational 10 forecasting systems further research is required whether an assimilation step of seven days is sufficient or better results could be achieved by increasing the assimilation frequency. Nevertheless, the use of SCA assimilation especially for large hilly regions (for which the amount of snow is not very high, and thus the representation of snow in the model can be easily wrong if the temperature has only a small error) could bring 15 significant improvement during spring periods in hydrological models.

Acknowledgements. The authors would like to thank Florian Pappenberger (ECMWF) for providing the snow depth observations and Jalal Younis (Czech Hydro-meteorological Institute) for providing the discharge observations in the Morava basin.

\section{References}

Anderson, E.: Snow Accumulation and Ablation Model - SNOW-17, Technical report, 2006 1340

Andreadis, K. M. and Lettenmaier, D. P.: Assimilating remotely sensed snow observations into a macroscale hydrology model, Adv. Water Resour., 29, 872-886, 2005. 1331, 1333, 1338

Arulampalam, M. S., Markell, S., Gordon N., and Clapp, T.: A tutorial on particle filters for online nonlinear/non-Gaussian Bayesian tracking, IEEE Tr. Signal Proces., 2002. 1335

Baker, J. E.: Reducing Bias and Inefficiency in the Selection Algorithm, Proceedings of the Second International Conference on Genetic Algorithms and their Application (Hillsdale, New Jersey: L. Erlbaum Associates), 14-21, 1987. 1336

\section{HESSD}

$8,1329-1364,2011$

\section{MODIS SCA \\ assimilation for \\ discharges \\ simulation}

G. Thirel et al.

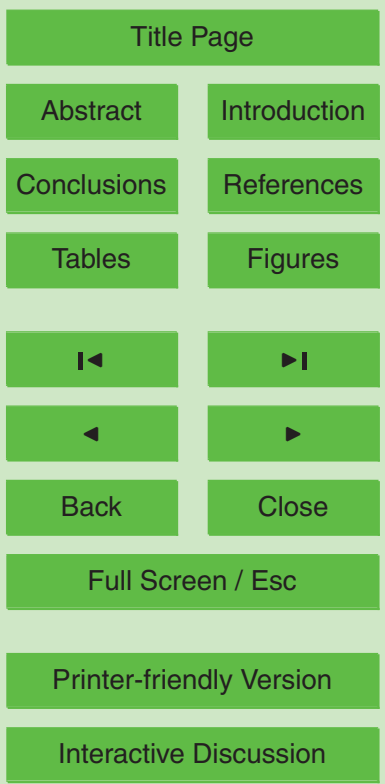


Barnett, T. P., Dumenil, L., Schlese, U., Roechner E., and Latif, M.: The effects of Eurasian snow cover on regional and global climate variations, J. Atmos. Sci., 46, 66-685, 1989. 1331

Bavera, D.: Water availability in mountain regions: estimation of Snow Water Equivalent using 5 ground data and MODIS images, PhD Dissertation, 156 pp., 2008. 1343

Bavera, D. and De Michele, C.: Snow water equivalent estimation in the Mallero basin using snow gauge data and MODIS images and fieldwork validation, Hydrol. Process., 23, 19611972, 2009. 1331, 1343

Boone, A. and Etchevers, P.: An intercomparison of three snow schemes of varying complexity coupled to the same land-surface model: Local scale evaluation at an Alpine site, J. Hydrometeorol., 2, 374-394, 2001. 1331

Bouttier, F. and Courtier, P.: Data assimilation concepts and methods, ECMWF Lecture Note, 1999. 1334

Burek, P. and de Roo, A.: LISFLOOD - distributed water balance and flood simulation model, 15 User manual (version December 2010), European Commission, under construction, 2011. 1341

Chin, T. M., Turmon, M. J., Jewell, J. B., and Ghil, M.: An ensemble-based smoother with retrospectively updated weights for highly nonlinear systems, Mon. Weather Rev., 135(1), 186-202, 2007. 1335

Chow, V. T., Maidment, D. R., and Mays, L. M.: Appl. Hydrol., McGraw-Hill, Singapore, 572 pp., 1988. 1340

Clark, M. P., Slater, A. G., Barrett, A. P., Hay, L. E., McCabe, G. J., Rajagopalan, B., and Leavesley, G. H.: Assimilation of snow covered area information into hydrologic and landsurface models, Adv. Water Resour., 29, 8, 1209-1221, 2006. 1331, 1332

Crow, W. T. and Ryu, D.: A new data assimilation approach for improving runoff prediction using remotely-sensed soil moisture retrievals, Hydrol. Earth Syst. Sci., 13, 1-16, 2009, http://www.hydrol-earth-syst-sci.net/13/1/2009/. 1331

Decker, K. L. M., Wang, D., Waite, C., and Scherbatskoy, T.: Snow removal and ambient air temperature effects on forest soil temperatures in northern Vermont, Soil Sci. Soc. Amer. J., 67, 1234-1242, 2003. 1331

De Roo, A.: LISFLOOD: a rainfall-runoff model for large river basins to assess the influence of land use changes on flood risk, in: Ribamod: river basin modelling, management and flood mitigation, edited by: Balabanis, P., Concerted action, European Commission, EUR 18287

\section{HESSD}

8, 1329-1364, 2011

\section{MODIS SCA \\ assimilation for \\ discharges \\ simulation}

G. Thirel et al.

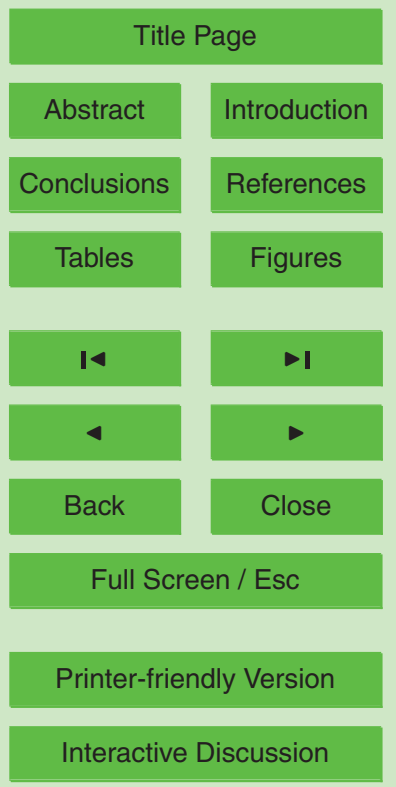


EN, 349-357, 1999. 1339

Doucet, A., de Freitas, N., and Gordon, N.: Sequential Monte Carlo Methods in Practice, Springer, New York, 2001. 1334, 1335

European Environment Agency, The European Topic Centre on Terrestrial Environment: Corine $5 \quad$ Land Cover rater database 2000-100m, 2000. 1339

Evensen, G.: The ensemble Kalman filter : Theorical formulation and practical implementation, Ocean Dynamics, 53, 343-367, 2003. 1334, 1335

Gafurov, A. and Bárdossy, A.: Cloud removal methodology from MODIS snow cover product, Hydrol. Earth Syst. Sci., 13, 1361-1373, doi:10.5194/hess-13-1361-2009, 2009. 1332

10 Gao, Y., Xie, H., Lu, N., Yao T., and Liang, T.: Toward advanced daily cloud-free snow cover and snow water equivalent products from Terra-Aqua MODIS and Aqua AMSR-E measurements, J. Hydrology, 385, 23-35, 2010. 1332

Hager, W. W.: Updating the inverse of a matrix, SIAM Rev., 31, 221-239, 1989. 1335

Hall, D. K., Riggs, G. A., and Salomonson, V. V.: MODIS/Terra Snow Cover 5-Min L2 Swath $15500 \mathrm{~m}$ V004, July 2003 to December 2006. Boulder, CO, USA: National Snow and Ice Data Center, Digital media, 2000. 1337

Karssenberg, D.: The value of environmental modelling languages for building distributed hydrological models, Hydrol. Process., 16, 2751-2766, 2002. 1339

Karssenberg, D., Schmitz, O., Salamon, P., de Jong, K., and Bierkens, M. F. P.: A software framework for construction of process-based stochastic spatio-temporal models and data assimilation, Environmental Modelling and Software, 25, 489-502, 2010. 1341

King, D., Daroussin, J., and Tavernier, R.: Development of a soil geographical database from the soil map of the European communities, Catena, 21, 37-56, 2004. 1339

Lindström, G., Johansson, B., Persson, M., Gardelin, M., and Bergström, S.: Development and test of the distributed HBV-96 hydrological model, J. Hydrol., 201, 272-288, 1997. 1340

Moradkhani, H., Hsu, K.-L., Gupta, H., and Sorooshian, S.: Uncertainty assessment of hydrologic model states and parameters, Water Resour. Res., 41, W05012, doi:10.1029/2004WR003604, 2005. 1335

Parajka, J. and Blöschl, G.: Validation of MODIS snow cover images over Austria, Hydrol. Earth $30 \quad$ Syst. Sci., 10, 679-689, doi:10.5194/hess-10-679-2006, 2006. 1331, 1332

Parajka, J. and Blöschl, G.: Spatio-temporal combination of MODIS images - potential for snow cover mapping, Water Resour. Res., 44, doi:10.1029/2007WR006204, 2008. 1332, 1337

Parajka, J., Pepe, M., Rampini, A., Rossi, S., and Blöschl, G.: A regional snow-line method

\section{HESSD}

8, 1329-1364, 2011

\section{MODIS SCA \\ assimilation for \\ discharges \\ simulation}

G. Thirel et al.

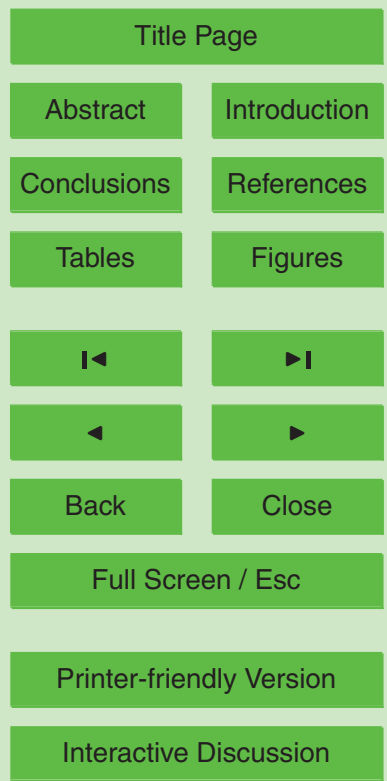


for estimating snow cover from MODIS during cloud cover, J. Hydrol., 381, 230-212, 2009. 1332,1337

Pulliainen, J. and Hallikainen, M.: Retrieval of regional snow water equivalent from space-borne passive microwave observations, Remote Sens. Environ., 75, 1, 76-85, 2001. 1331

5 Quintana Seguí, P., Le Moigne, P., Durand, Y., Martin, E., Habets, F., Baillon, M., Canellas, C., Franchisteguy, L., and Morel, S.: Analysis of near surface atmospheric variables : Validation of the SAFRAN analysis over France, J. Appl. Meteorol. Clim., 47, 92-107, 2008. 1342

Reichle, R. H., McLaughlin, D. B., and Entekhabi, D.: Hydrologic data assimilation with the Ensemble Kalman Filter, Mon. Weather Rev., 130, 1, 103-114, 2002. 1331

10 Rijks, D., Teres, J. M., and Vossen, P.: Agrometeorological Applications for Regional Crop Monitoring and Production Assessment, Tech. Rep. EUR 17735 EN, Eur. Comm. Joint Res. Cent., Ispra, Italy, 1998. 1339

Rodell, M. and Houser, P. R.: Updating a land surface model with MODIS-derived snow cover, J. Hydrometeorol., 8, 1064-1075, 2004. 1331, 1332

15 Roy, A., Royer, A., and Turcotte, R.: Improvement of springtime streamflow simulations in a boreal environment by incorporating snow-covered area derived from remote sensing data, J. Hydrol., 390, 35-44, 2010. 1331, 1332

Salamon. P. and Feyen, L.: Assessing parameter, precipitation, and predictive uncertainty in a distributed hydrological model using sequential data assimilation with the particle filter, $\mathrm{J}$. 20 Hydrol., 376, 428-442, 2009. 1331

Simon, D.: Optimal State Estimation: Kalman, H Infinity, and Nonlinear Approaches, WileyInterscience, Hoboken, New Jersey, 2006. 1334, 1335

Slater, A. G. and Clark, M. P.: Snow data assimilation via an Ensemble Kalman Filter, J. Hydrometeorol., 7, 3, 478-493, 2006. 1332

Speers, D. D. and Versteeg, J. D.: Runoff forecasting for reservoir operations - the past and the future, Proceedings 52 ${ }^{\text {nd }}$ Western Snow Conference, 149-156, 1979. 1340

Su, H., Yang, Z.-L., Niu, G.-Y., and Dickinson, R. E.: Enhancing the estimation of continentalscale snow water equivalent by assimilating MODIS snow cover with the ensemble Kalman filter, J. Geophys. Res., 113, doi:10.1029/2007JD009232, 2008. 1331, 1333, 1338

30 Thirel, G., Martin, E., Mahfouf, J.-F., Massart, S., Ricci, S., and Habets, F.: A past discharges assimilation system for ensemble streamflow forecasts over France - Part 1: Description and validation of the assimilation system, Hydrol. Earth Syst. Sci., 14, 1623-1637, doi:10.5194/hess-14-1623-2010, 2010. 1331

HESSD

8, 1329-1364, 2011

\section{MODIS SCA \\ assimilation for \\ discharges \\ simulation}

G. Thirel et al.

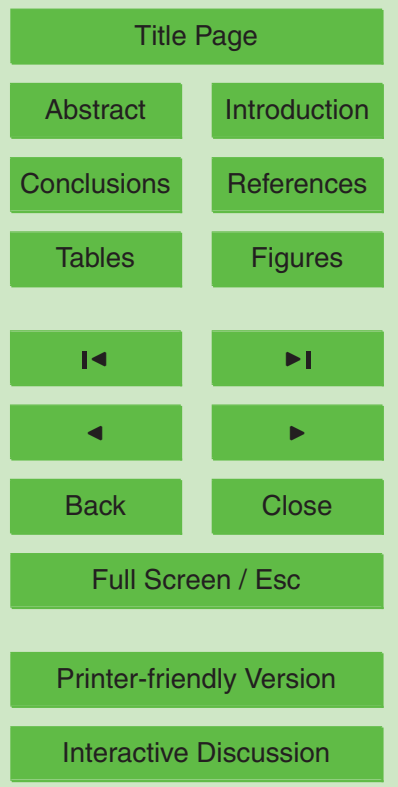


Todini, E.: The ARNO rainfall-runoff, J. Hydrol., 175, 339-382, 1996. 1340

Van der Knijff, J., Younis, J., and De Roo, A.: LISFLOOD - a GIS-based distributed model for river basin scale water balance and flood simulation, Int. J. Geographical Information Science, 1-24 November, 2008. 1339

5 van Leeuwen, P. J.: Particle Filtering in Geophysical Systems, Mon. Weather Rev., 137, 40894114, 2009. 1335

Wösten, J. H. M., Lilly, A., Nemes, A., and Le Bas, C.: Development and use of a database of hydraulic properties of European soils, Geoderma, 90(3-4), 169-185, 1999. 1339

Zaitchik, B. and Rodell, M.: Forward-looking assimilation of MODIS-derived snow-covered area into a land surface model, J. Hydrometeorol., 10, 130-148, 2008. 1331, 1333, 1338, 1339

Zhao, R. J. and Liu, X. R.: The Xinanjiang model, Computer Models of Watershed Hydrology, edited by: Singh, V. P., 215-232, 1995. 1340

\section{HESSD}

8, 1329-1364, 2011

\section{MODIS SCA \\ assimilation for discharges simulation}

G. Thirel et al.

\section{Title Page}

\section{Abstract} Introduction

Conclusions References

Tables Figures
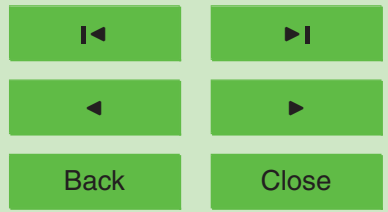

Back

Full Screen / Esc

Printer-friendly Version

Interactive Discussion 


\section{HESSD}

$8,1329-1364,2011$

Table 1. Snow categories in the MODIS classification (left part) and as used for the preprocessing (right part).

\begin{tabular}{rlcc}
\hline \multicolumn{2}{c}{ MODIS classification } & \multicolumn{2}{c}{ Used classification } \\
Value & Data & Value & Data \\
\hline 0 & Missing & & \\
1 & No decision & Missing value & "we don't know" \\
11 & Night & & \\
50 & Cloud obscured & & \\
254 & Detector saturated & & \\
255 & Fill & & No snow \\
25 & Snow-free land & & \\
37 & Lake or inland water & 0 & Snow \\
39 & Open water (ocean) & & \\
\hline 100 & Snow-covered lake ice & 1 & \\
200 & Snow & & \\
\hline
\end{tabular}

\section{MODIS SCA assimilation for discharges simulation}

G. Thirel et al.

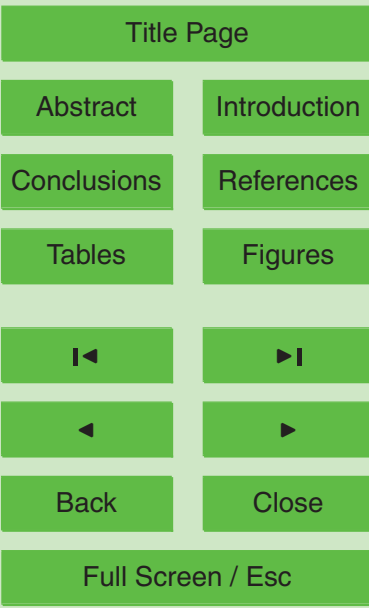

Printer-friendly Version

Interactive Discussion 


\section{HESSD}

8, 1329-1364, 2011

\section{MODIS SCA \\ assimilation for discharges simulation}

G. Thirel et al.

Table 2. Percentage of cloud coverage, averaged over the period 10 January 2004-10 December 2006, for the different improvement methods.

\begin{tabular}{ccccc}
\hline Aqua+Terra & +Day -1 & +Days -2/-3 & +Days -4/-5 & +Days -6/-7 \\
\hline 48.6 & 33.2 & 16.8 & 9.0 & 4.9
\end{tabular}

Title Page

Abstract Introduction

Conclusions

References

Tables

Figures

14

4

Back

Full Screen / Esc

Printer-friendly Version

Interactive Discussion 


\section{HESSD}

$8,1329-1364,2011$

\section{MODIS SCA \\ assimilation for discharges simulation}

Table 3. Scores for the assimilation (for the mean of the members or of the particles) using the three altitudinal zones, averaged over the period 10 January 2004-10 December 2006. In-situ snow scores are calculated over the period 5 April 2005-10 December 2006.

\begin{tabular}{l|ccc|cc|cc}
\hline & \multicolumn{3}{|c|}{ Discharge scores } & \multicolumn{2}{c|}{ MODIS snow scores } & \multicolumn{2}{c}{ In-situ snow scores } \\
Experiment & Rat.-RMSE & Rat.-Bias & Nash & Rat.-RMSE & Rat.-Bias & Rat.-RMSE & Rat.-Bias \\
\hline No assimil. & 0.73 & 0.13 & 0.76 & 8.97 & 3.36 & 13.86 & 4.13 \\
EnKF 20 mb & 0.80 & 0.11 & 0.70 & 7.11 & 3.02 & 14.36 & 4.78 \\
EnKF 50 mb & 0.80 & 0.11 & 0.71 & 7.09 & 3.02 & 12.83 & 4.13 \\
Pf 50 pa & 0.68 & 0.09 & 0.79 & 6.81 & 2.65 & 14.05 & 4.19 \\
Pf 200 pa & 0.70 & 0.09 & 0.78 & 6.77 & 2.63 & 9.30 & 2.04 \\
\hline
\end{tabular}

Title Page

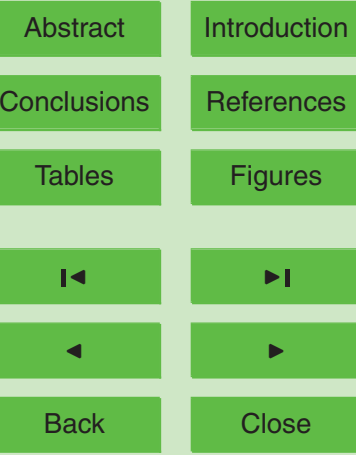

Full Screen / Esc

Printer-friendly Version

Interactive Discussion 


\section{HESSD}

$8,1329-1364,2011$

\section{MODIS SCA \\ assimilation for discharges simulation}

Table 4. Scores for the assimilation (for the mean of the members or of the particles) using the seven sub-basins zones, averaged over the period 10 January 2004-10 December 2006. In-situ snow scores are calculated over the period 5 April 2005-10 December 2006.

\begin{tabular}{l|ccc|cc|cc}
\hline & \multicolumn{3}{|c|}{ Discharge scores } & \multicolumn{2}{c|}{ MODIS snow scores } & \multicolumn{2}{c}{ In-situ snow scores } \\
\hline Experiment & Rat.-RMSE & Rat.-Bias & Nash & Rat.-RMSE & Rat.-Bias & Rat.-RMSE & Rat.-Bias \\
No assimil. & 0.73 & 0.13 & 0.76 & 8.97 & 3.36 & 13.86 & 4.13 \\
EnKF 20 mb & 0.99 & 0.22 & 0.56 & 5.10 & 2.17 & 15.81 & 5.34 \\
EnKF 50 mb & 0.91 & 0.19 & 0.63 & 6.00 & 2.46 & 14.62 & 4.88 \\
Pf 50 pa & 0.70 & 0.10 & 0.77 & 6.72 & 2.61 & 9.02 & 1.83 \\
Pf 200 pa & 0.70 & 0.08 & 0.78 & 6.79 & 2.64 & 12.48 & 3.52 \\
\hline
\end{tabular}

G. Thirel et al.

Title Page

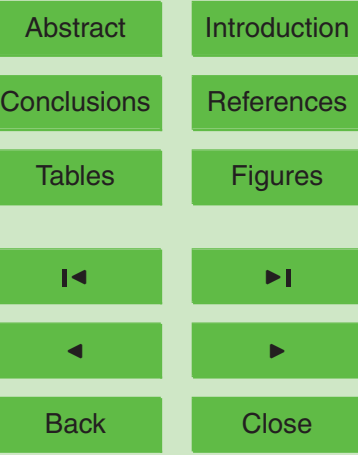

Full Screen / Esc

Printer-friendly Version

Interactive Discussion 
HESSD

8, 1329-1364, 2011

\section{MODIS SCA \\ assimilation for discharges simulation}

G. Thirel et al.

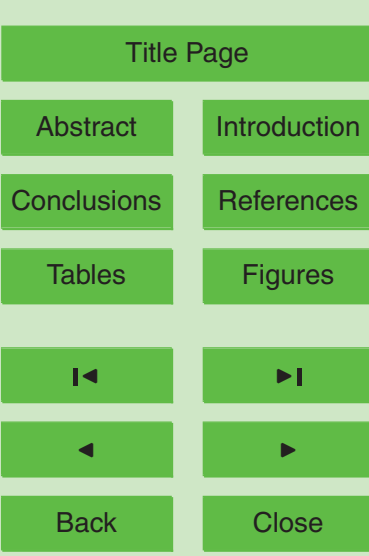

Full Screen / Esc

Printer-friendly Version

Interactive Discussion 


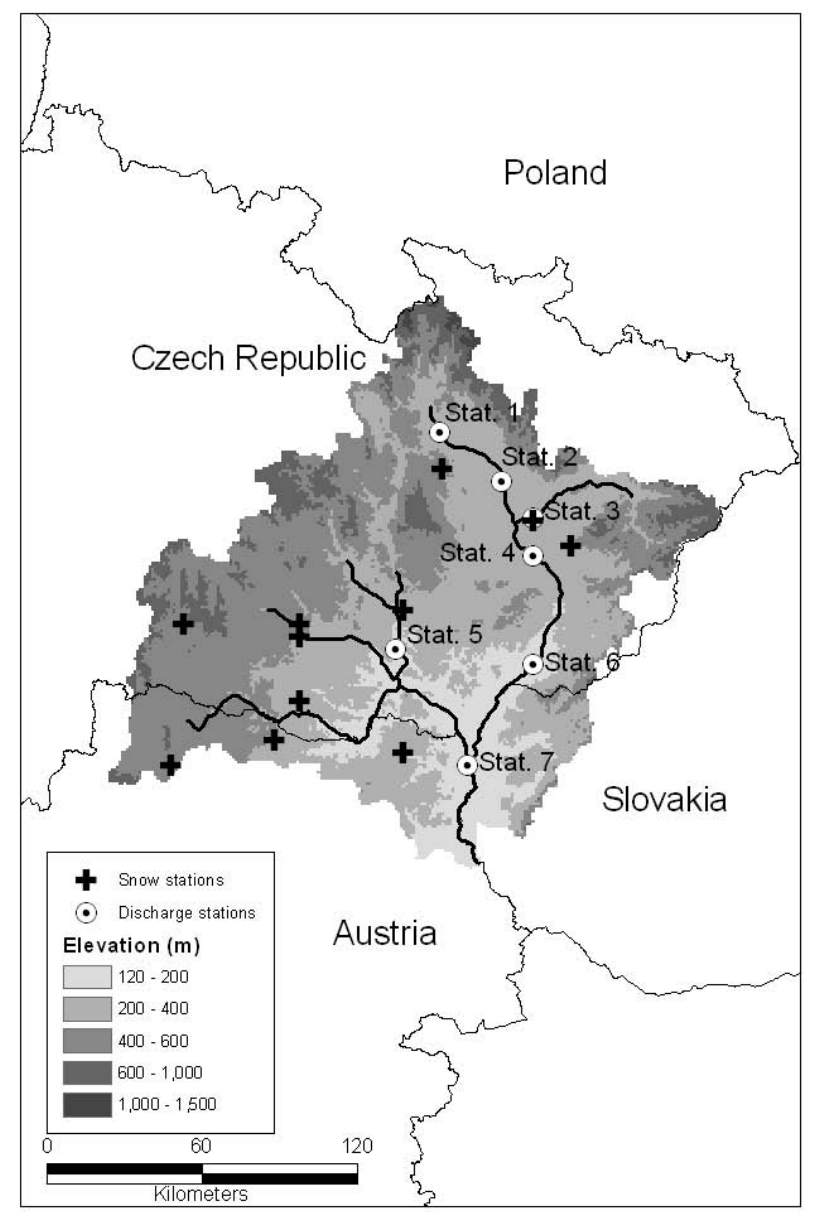

\section{HESSD}

8, 1329-1364, 2011

\section{MODIS SCA assimilation for discharges simulation}

G. Thirel et al.

Title Page

\section{Abstract}

Introduction

Conclusions

References

Tables

Figures

14

4

Back

Full Screen / Esc

Printer-friendly Version

Interactive Discussion 

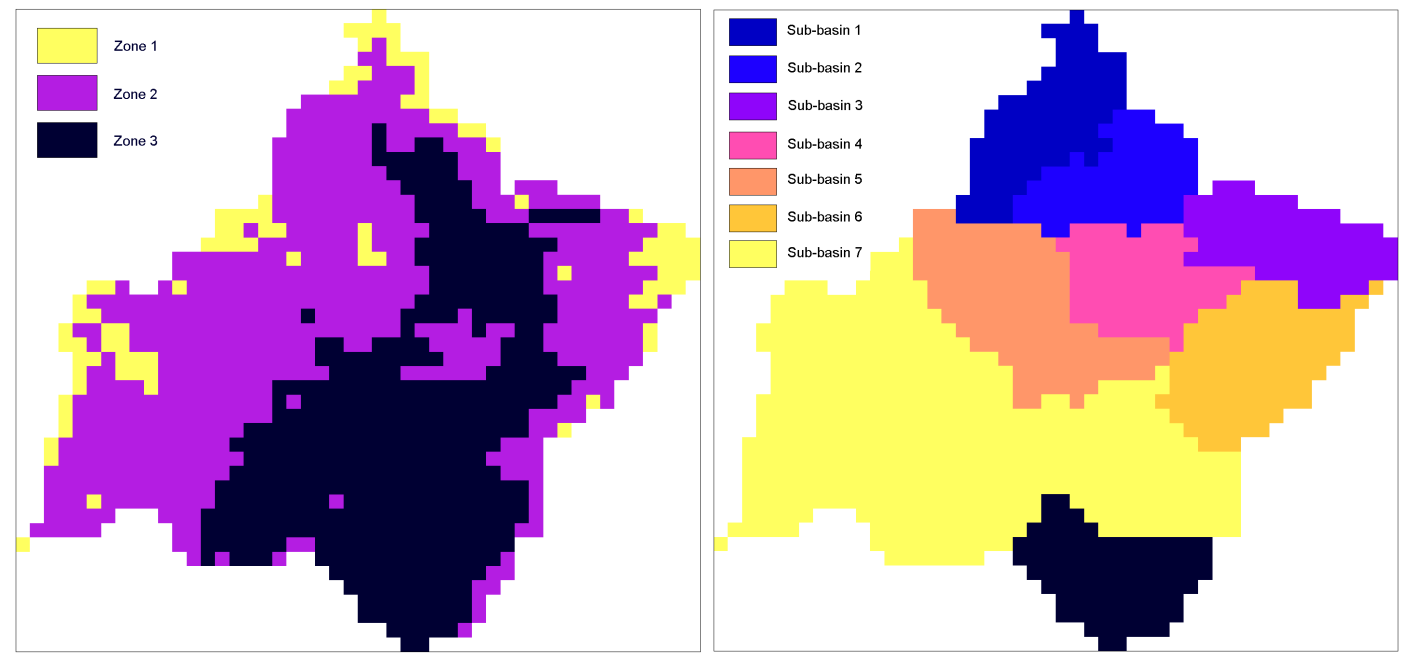

Fig. 3. Maps of the different zones used for the assimilation systems: the three altitudinal zones (left) and the seven sub-basins-based zones (right; the black part was not taken into account for the particle filter).

\section{HESSD}

8, 1329-1364, 2011

\section{MODIS SCA assimilation for discharges simulation}

G. Thirel et al.

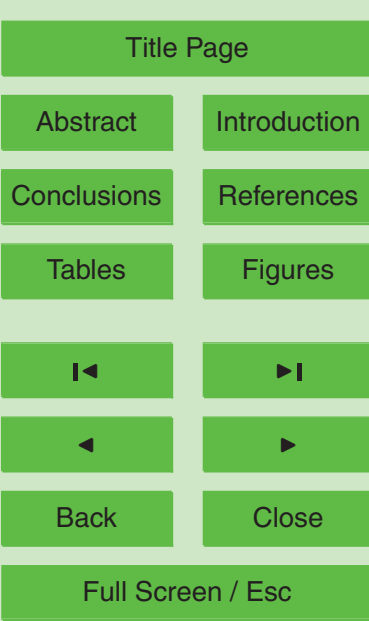

Printer-friendly Version

Interactive Discussion 


\section{HESSD}

$8,1329-1364,2011$
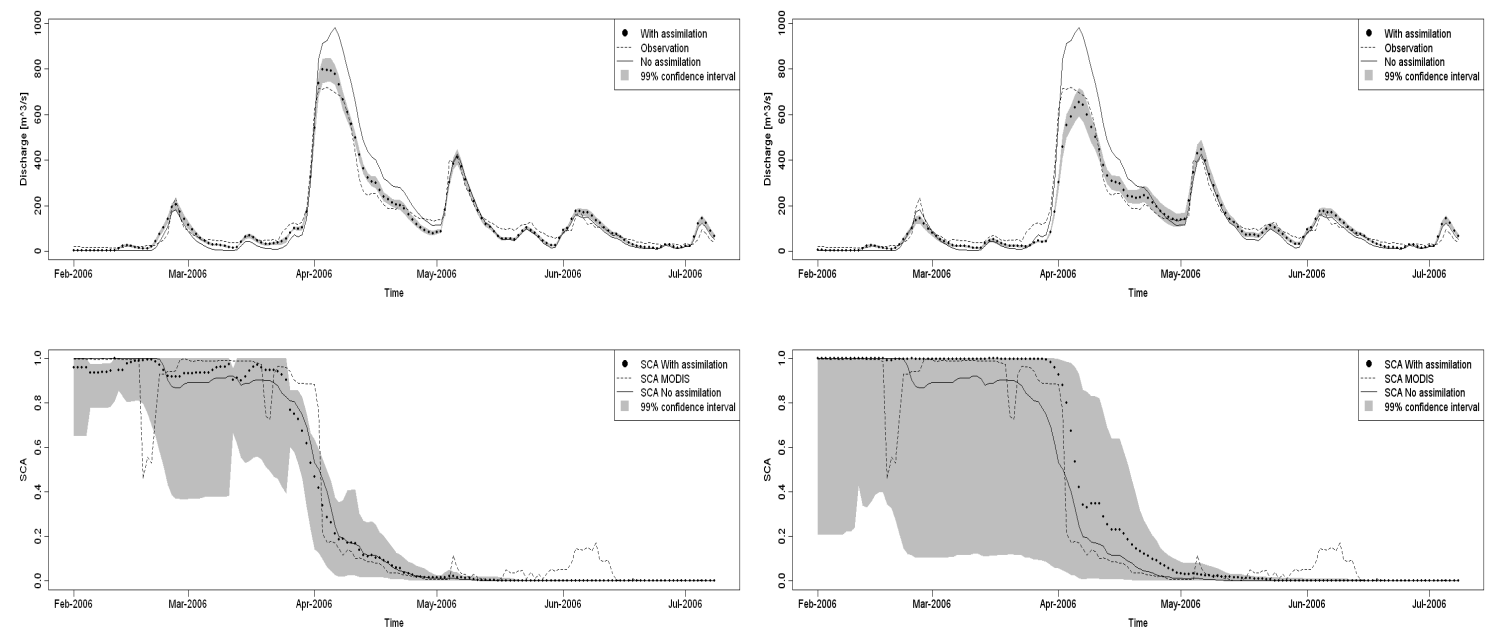

Fig. 4. Discharge at station 6 (top) and average snow cover area over its upstream area (bottom), from 1 February 2006 to 10 July 2006 for the particle filter using 200 particles and the seven zones (left) and the EnKF using 50 members and the three zones (right). Observations are in dashed black, the simulations without assimilation are the black lines, the ranges of the uncertainty of the 50 particles (99\%) are in grey, and the average of the assimilated simulations are bullets.

\section{MODIS SCA assimilation for discharges simulation}

G. Thirel et al.

\section{Title Page}

\section{Abstract}

Conclusions

Tables

14

4

Back
Introduction

References

Figures

$>$ I

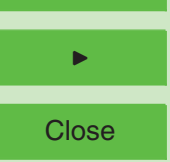

Full Screen / Esc

Printer-friendly Version

Interactive Discussion 


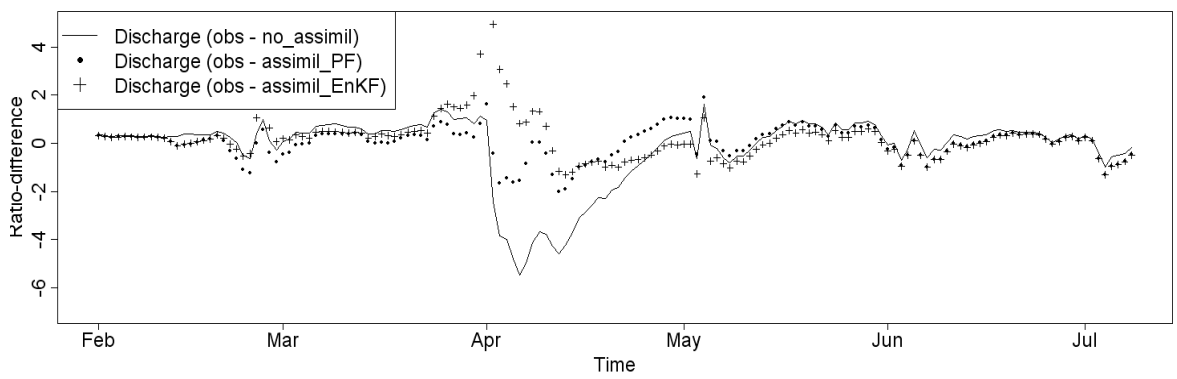

\section{HESSD}

8, 1329-1364, 2011

\section{MODIS SCA \\ assimilation for discharges simulation}

G. Thirel et al.

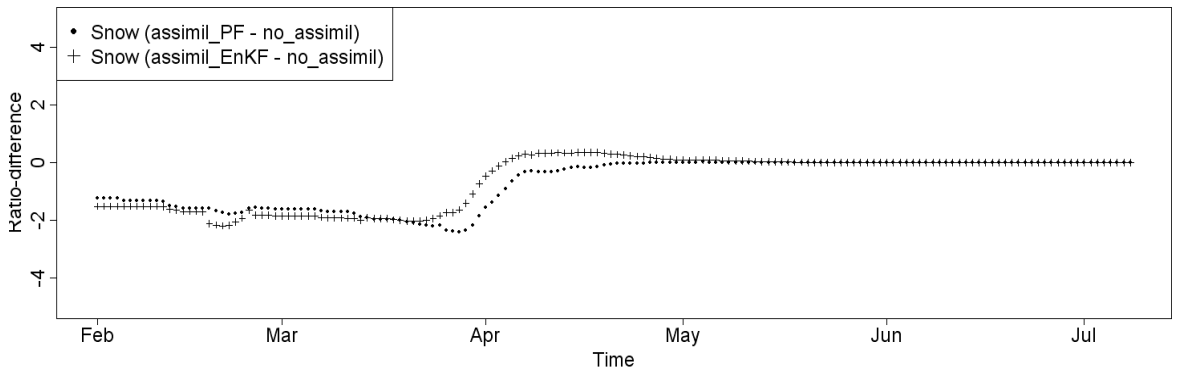

Title Page

Abstract Introduction

Conclusions References

Tables Figures

14 - I

Fig. 5. Time series of the differences for discharges (top) between the observations and the experiments for the gauge station 6 from 1 February 2006 to 10 July 2006 for the particle filter using 200 particles and the seven zones, and the EnKF using 50 members and the three zones. Time series representing the differences between the SWE of the assimilation experiments and of the no assimilation run are plotted on the bottom graph. The time series are normalized, i.e. divided by the mean of the no assimilation simulation.

4

Back

Full Screen / Esc

Printer-friendly Version

Interactive Discussion 


\section{HESSD}

8, 1329-1364, 2011
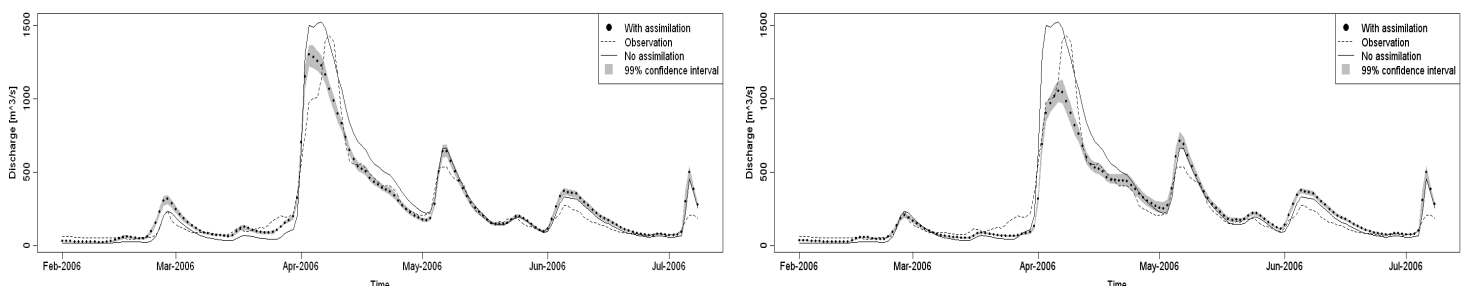

\section{MODIS SCA assimilation for discharges simulation}

G. Thirel et al.
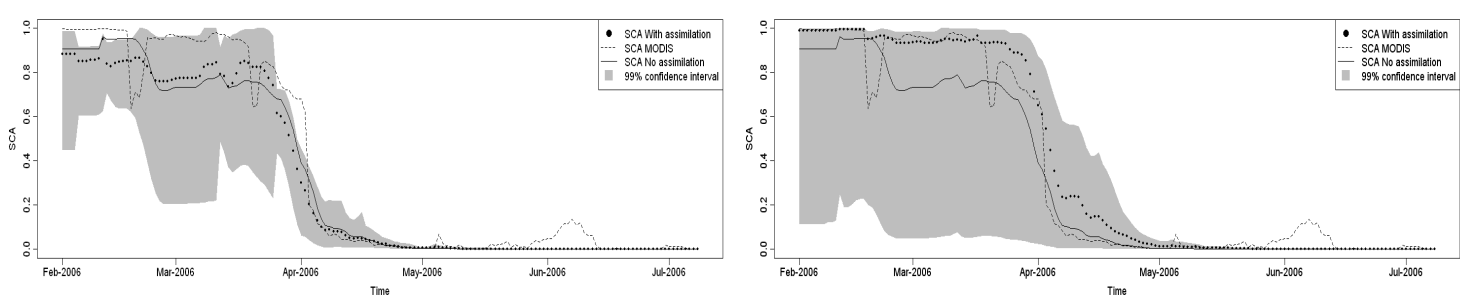

Fig. 6. Discharge at station 7 (top) and average snow cover area over its upstream area (bottom), from 1 February 2006 to 10 July 2006 for the particle filter using 200 particles and the seven zones (left) and the EnKF using 50 members and the three zones (right). Observations are in dashed black, the simulations without assimilation are the black lines, the ranges of the uncertainty of the 50 particles (99\%) are in grey, and the average of the assimilated simulations are bullets. a

西




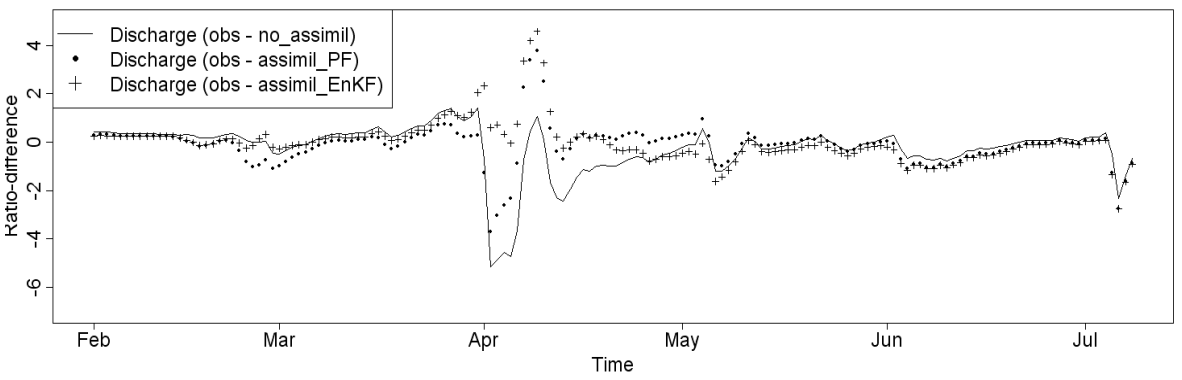

HESSD

8, 1329-1364, 2011

\section{MODIS SCA \\ assimilation for discharges simulation}

G. Thirel et al.

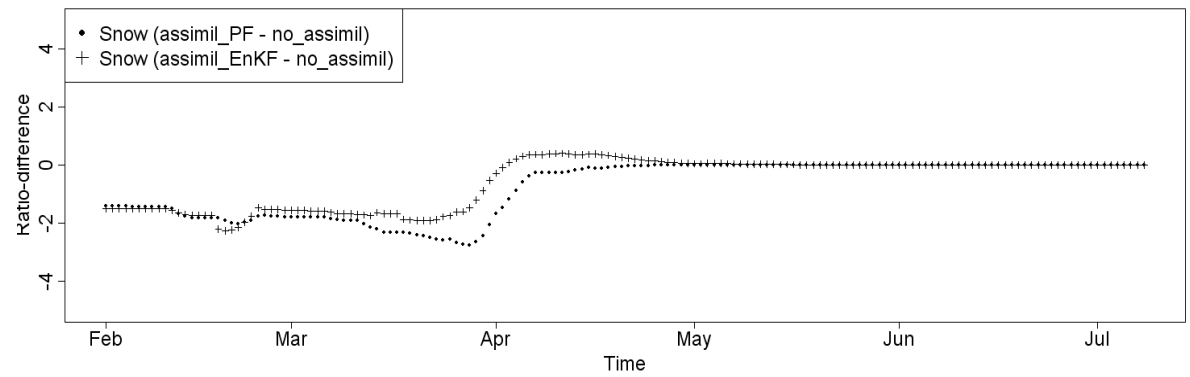

Title Page

Abstract Introduction

Conclusions

References

Tables

Figures

14

$\rightarrow$ I

Fig. 7. Time series of the differences for discharges (top) between the observations and the experiments for the gauge station 7 from 1 February 2006 to 10 July 2006 for the particle filter using 200 particles and the seven zones, and the EnKF using 50 members and the three zones. Time series representing the differences between the SWE of the assimilation experiments and of the no assimilation run are plotted on the bottom graph. The time series are normalized, i.e. divided by the mean of the no assimilation simulation.

4

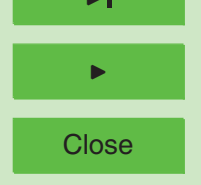

Full Screen / Esc

Printer-friendly Version

Interactive Discussion 